\title{
Caloric restriction inhibits renal artery ageing by reducing endothelin-1 expression
}

\author{
Xiao-Hua Wang, Qiang-Guo Ao, Qing-Li Cheng \\ Department of Nephrology, The Second Medical Center, Chinese PLA General Hospital, Beijing, China \\ Contributions: (I) Conception and design: XH Wang, QL Cheng; (II) Administrative support: QG Ao; (III) Provision of study materials or patients: \\ XH Wang; (IV) Collection and assembly of data: XH Wang; (V) Data analysis and interpretation: XH Wang; (VI) Manuscript writing: All authors; (VII) \\ Final approval of manuscript: All authors. \\ Correspondence to: Dr. Qing-Li Cheng. Department of Nephrology, The Second Medical Center, Chinese PLA General Hospital, No. 28, Fuxing \\ Road, Beijing 100853, China. Email: chengqingli_med@163.com.
}

Background: The renal artery plays a central role in renal perfusion and is critical for proper renal function. Ageing is an independent risk factor for both impaired renal function and vascular disorders, and associated with an increase in the expression of the vasoconstrictor endothelin-1 (ET-1), and caloric restriction (CR) without malnutrition has been shown to be an effective inhibitor of renal dysfunction induced by ageing. The objective of this study was to determine whether CR-mediated alleviation of renal dysfunction is mediated by ET-1 expression.

Methods: The young (2 months, $2 \mathrm{M}$ ) and old (12 months, $12 \mathrm{M})$ Sprague-Dawley male rats were used and fed ad libitum. The 12-month-old rats were further divided into $12 \mathrm{M}$ and $12 \mathrm{M}$-caloric restriction (CR) (30\% calorie restriction). After 8 weeks, the renal tissues were showed by PAS staining, and age-related metabolic parameters and renal functions were detected in each group of rats. The inflammatory cytokines of interleukin (IL)-6, IL-1 $\beta$, tumor necrosis factor alpha (TNF- $\alpha$ ), and transforming growth factor beta 1 (TGF- $\beta 1$ ) were analyzed using ELISA. The mRNA and protein expression in the renal artery were analysis by qRT-PCR and Immunoblot analysis.

Results: Ageing was associated with significant increases in $24 \mathrm{~h}$ urine protein content and serum triglyceride and cholesterol in $12 \mathrm{M}$ rats, both of which were significantly inhibited in $12 \mathrm{M}-\mathrm{CR}$. The mRNA expression and the secretion of IL-6, IL-1 $\beta, T N F-\alpha$, and TGF- $\beta 1$ in the renal artery was significantly increased with ageing and inhibited by CR. CR also inhibited ageing-induced $E d n 1$ (encoding ET-1) mRNA and protein expression in the renal artery. In addition, CR could regulate ET-1 expression by inhibiting the activation of NF- $\mathrm{KB}$ signaling and activation and induction in the expression of NF-E2-related factor 2 (Nrf2) and histone deacetylase and gene repressor sirtuin 1 (SIRT1), both of which play a central role in mitigating oxidative stress in young rats.

Conclusions: Moderate CR can reverse the ageing related kidney dysfunction by reducing the ET-1 expression. CR might be used as an alternative to prevent the ageing induced renal artery dysfunction.

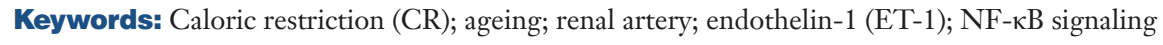

Submitted Apr 07, 2021. Accepted for publication May 28, 2021.

doi: 10.21037/atm-21-2218

View this article at: https://dx.doi.org/10.21037/atm-21-2218

\section{Introduction}

There has been a significant increase in both life expectancy at birth and life expectancy beyond the age of 65 years (1). However, this has also raised concerns about health care spending, given that approximately $80 \%$ and $50 \%$ of those over 65 years suffer from one and two chronic disease, respectively (2).

More than $50 \%$ of adults older than 70 years of age are diagnosed with chronic kidney disease, which also presents 
a heightened risk of mortality from cardiovascular disease $(3-7)$. The renal artery provides renal perfusion and is absolutely critical for proper renal function (8). Ageing is an independent risk factor for both impaired renal function and vascular disorders (9), highlighting the importance of the homeostasis of renal arterial pathophysiology $(10,11)$. Vascular disorders, inclusive of inflammation, fibrosis, calcification, and decreased vasodilation, have been shown to result in ageing-associated stiffening of the renal arteries, leading to the development of tubulointerstitial fibrosis and glomerulosclerosis (10-12). Ageing is also associated with a pro-inflammatory shift in circulating cytokine expression profiles (13).

Endothelin-1 (ET-1) is a potent vasoconstrictor synthesized by vascular endothelial cells that is normally present at low plasma concentrations (14). ET-1 plays a significant role in kidney physiology and pathology (15), highlighted by the fact that ET-1 transgenic mice undergo spontaneous kidney fibrosis even in the absence of hypertension (16). Ageing is associated with an increase in ET-1 levels in the renal vasculature (17). Elevated ET-1 can increase reactive oxygen species (ROS) $(18,19)$, which in turn can increase the uptake of oxidized low-density lipoprotein (ox-LDL) by increasing the expression of its cognate receptor lectin-like oxidized low-density lipoprotein receptor-1 (LOX-1) (20), cumulatively contributing to endothelial dysfunction. Indeed, pre-clinical studies with endothelin receptor antagonists have shown promising results in alleviating ageing-induced impairment of renal function $(21,22)$.

Caloric restriction (CR) can reduce the ageing process and related organ dysfunction in most species (23). CR without malnutrition is a dietary regimen that delays ageing and extends the lifespan (24). More importantly, studies in mice and rat models of ageing have shown that CR exerts significant cerebrovascular protective effects, improves cortical microvascular density and endothelial function (25), and counteracts ageing-induced alterations in renal function, including glomerulosclerosis and alterations in glomerular filtration (6). Anti-oxidative and anti-inflammatory factors present in the sera of rats were found to produce significant age-related effects in cultured endothelial cells (25). CR also improved vascular health by eliciting changes in the levels of circulating neuroendocrine factors (26). More recently, a study using the non-human primate Macaca mulatta model showed that CR induced pro-angiogenic effects in cultured endothelial cells (27). CR can also reduce circulating pro- inflammatory cytokines (28).

Given this background, the objective of the current study was to investigate whether CR counteracts ageing-induced alterations in renal function and inflammatory cytokines by impacting ET-1 levels. We found that ET-1 messenger RNA (mRNA) and protein expression were increased ex vivo in the renal artery segments of 12-month-old rats compared to 2-month-old rats, which was reversed when rats were subjected to CR. Functional assays showed that CR alleviated renal dysfunction and decreased the expression of pro-inflammatory cytokines by decreasing ET-1 expression.

We present the following article in accordance with the ARRIVE reporting checklist (available at https://dx.doi. org/10.21037/atm-21-2218).

\section{Methods}

\section{Animals}

All animal experiments were approved by the Institutional Animal Care and Use Committee of the Second Medical Center, Chinese PLA General Hospital under a project license (No. PLA301-2020-3XNK-2162), in compliance with all applicable international, national or institutional guidelines for the care and use of animals. Male Sprague-Dawley (SD) rats were housed (one rat per cage) under specific pathogenfree conditions at $22 \pm 1{ }^{\circ} \mathrm{C}, 40 \%$ humidity, $12 \mathrm{~h}$ light cycle, and having access to water ad libitum. The experiments were carried out using animals of two ages: 2-month-old male SD rats that were fed ad libitum $(2 \mathrm{M}, \mathrm{n}=8)$ and 12-monthold male SD rats $(\mathrm{n}=16)$ that were further divided into two subgroups ( $\mathrm{n}=8$ per group); $12 \mathrm{M}$ and $12 \mathrm{M}-\mathrm{CR}$ (30\% CR). For the final 8 weeks of the experiment, the $12 \mathrm{M}$ group was fed ad libitum as usual, whereas the $12 \mathrm{M}$-CR group were fed with only $70 \%$ food. This was confirmed using the food amounts ingested by the $12 \mathrm{M}$ group over the same time. Before the end of experiments, the animals were placed in metabolic cages, and $24 \mathrm{~h}$ urine was collected as described before (22). Urine protein content was measured by turbidity assay using 3\% sulfosalicylic acid (Chondrex Inc., Catalogue 9040, Seattle, USA).

\section{Sample preparation}

At the end of the experimental time points, blood samples were obtained from the tail vein. All rats were subsequently anesthetized by an intraperitoneal injection of sodium pentobarbital (40 mg/kg of body weight) and were sacrificed 
Table 1 Primers sequences

\begin{tabular}{ll}
\hline Name of primer & Sequences (5'-3') \\
\hline ET-1-F & ACTTACTTCCCACAAAGACCAC \\
ET-1-R & GCTCGGAGTTCTTGTCTGC \\
VEGF-F & TGGACCCTGGCTTTACTGCT \\
VEGF-R & TGCGCTGGTAGACGTCCATG \\
LOX-1-F & AAATCCCAACCACCCATG \\
LOX-1-R & TCTGTAAAGAAACGCCCCTG \\
IL-6-F & GATACCACCCACAACAGA \\
IL-6-R & ATACAATCAGAATTGCCAT \\
IL-1 $\beta-F$ & AAATAGCAGCTTTCGACAGT \\
IL-1 $\beta-R$ & AGATTTGAAGCTGGATGCTC \\
TNF- $\alpha-F$ & TCCATGGCCCAGACCCTC \\
TNF- $\alpha-R$ & TCCAGCTGCTCCTCCGCTTG \\
TGF- $\beta-F$ & GGAATACAGGGCTTCGCTT \\
TGF- $\beta-R$ & AAGGGTCGGTTCATGTCA \\
GAPDH-F & CTGAACGTGAAATTGTCCGAGA \\
GAPDH-R & TTGCCAATGGTGATGACCTG \\
\hline
\end{tabular}

by decapitation. Kidney tissues were removed and perfused with ice-cold isotonic phosphate-buffered saline (PBS; $\mathrm{pH}$ 7.4), to remove any remaining blood, and the remaining tissue was immediately frozen in liquid nitrogen and stored at $-80^{\circ} \mathrm{C}$ until further processing.

\section{qRT-PCR}

Total RNA from renal artery tissue was extracted using TRIZOL (Thermo Fisher Scientific, MA, USA) and RNA concentrations of samples were measured using a NanoDrop ND-1000 spectrophotometer (NanoDrop, USA). The total RNA was reverse transcribed into cDNA using the PrimeScript RT reagent Kit (TaKaRa, Dalian, China) and these were quantified by qRT-PCR with a SYBR Green PCR kit (TaKaRa, Dalian, China). Primers used in this study are listed in Table 1. The following thermocycling conditions were used: Initial denaturation at $95^{\circ} \mathrm{C}$ for $2 \mathrm{~min}$; 40 cycles of $94^{\circ} \mathrm{C}$ for $20 \mathrm{~s}$ and $60^{\circ} \mathrm{C}$ for 20 $\mathrm{s}$, and a final extension at $72{ }^{\circ} \mathrm{C}$ for $30 \mathrm{~s}$. Glyceraldehyde3 -phosphate dehydrogenase $(G A P D H)$ expression was used for data normalization All assays were performed in triplicate and were repeated ${ }^{3}$ three times and the relative
mRNA expression was quantified using the $2^{-\Delta \Delta C q}$ method.

\section{Immunoblotting}

Total proteins were extracted using RIPA lysis buffer (Sigma, USA). Protein (50 $\mu \mathrm{g}$ each) were separated by $10 \%$ SDSPAGE and then transferred onto a polyvinylidene difluoride (PVDF) membrane. Nonspecific interactions were blocked using $5 \%$ non-fat milk for $2 \mathrm{~h}$, then after three washes of 15 min each with $1 \times$ TBST buffer, the membranes were incubated with the corresponding primary antibodies (all antibodies were purchased from Cell Signaling Technology, MA, USA and used at 1:1,000 dilution) overnight at $4^{\circ} \mathrm{C}$. After three washes of 15 min each with $1 \times$ TBST buffer, the membranes were incubated in peroxidase-labeled secondary antibodies (anti-rabbit IgG, 1:2,000, I5006MSDS, Sigma, USA) for $2 \mathrm{~h}$. The protein bands were visualized using ECL system (Thermo Fisher Scientific, MA, USA) and intensity was analyzed using Image Lab ${ }^{\mathrm{TM}}$ Software (Bio-Rad, USA).

\section{Periodic acid-Schiff stain (PAS) staining}

$10-\mu \mathrm{m}$ sections were cut from paraffin block and placed on an individual lysine-coated slide, and PAS staining was performed using the PAS Staining Kit (Millipore Sigma). Briefly, slides were deparaffinized and hydrated to deionized water and then immersed in Periodic acid solution for $5 \mathrm{~min}$ at $25^{\circ} \mathrm{C}$ before being rinsed five times with distilled water and immersed in Schiff's reagent for $15 \mathrm{~min}$ at $25^{\circ} \mathrm{C}$. The slides were then counterstained with hematoxylin solution for $90 \mathrm{sec}$ and rinsed in running tap water, then dehydrated, cleared, and mounted. Images were obtained using a microscope (Axiophot; Carl Zeiss Meditec, Inc., Thornwood, NY, USA).

\section{ELISA}

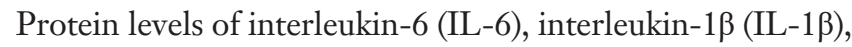
tumor necrosis factor alpha (TNF- $\alpha$ ), and transforming growth factor- $\beta$ (TGF- $\beta$ ) were analyzed using a ELISA kit (Yanjin Biotechnology Co., Shanghai, China), as per manufacturer's instructions. The absorbance was measured at $450 \mathrm{~nm}$ using a $680 \mathrm{XR}$ microplate reader (Bio-Rad, Hercules, CA, USA).

\section{Statistical analysis}

Statistical analyses were performed using GraphPad Prism 
A
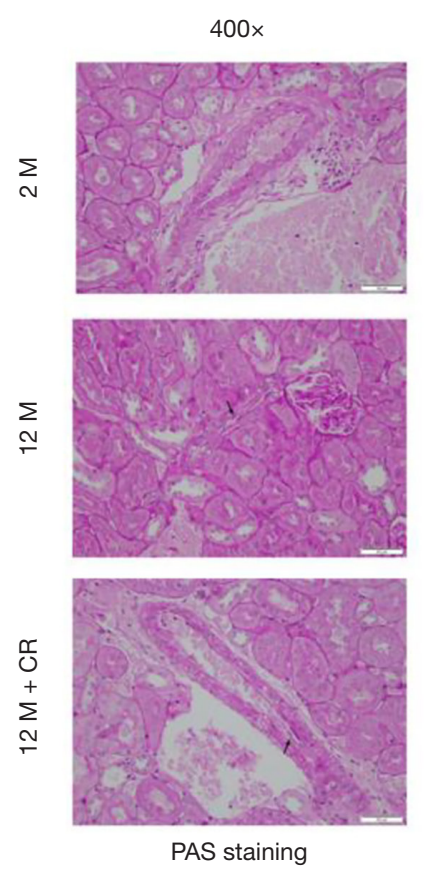

B

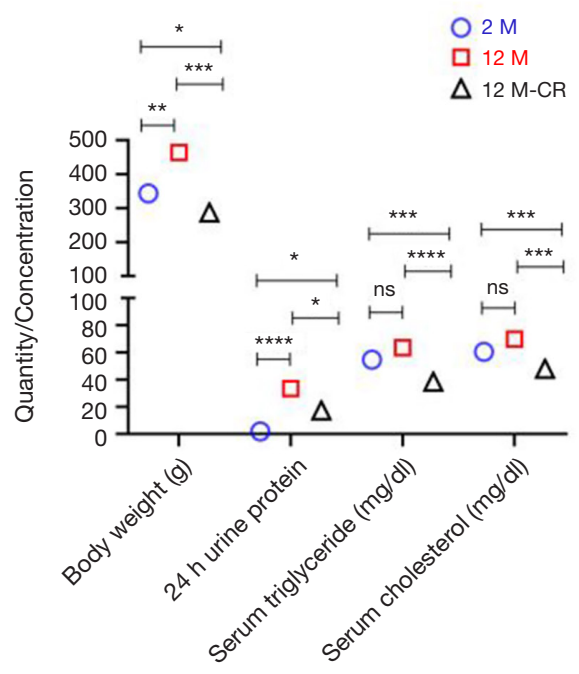

Figure 1 Ageing-induced renal dysfunction and changes in metabolic parameters are inhibited by calorie restriction (CR). (A) PAS staining of renal tissues obtained from young ( 2 months-old) and aged (12 months-old) rats fed ad libitum ( 2 and $12 \mathrm{M}$, respectively) or under 8 weeks of caloric restriction (12 M-CR) SD rats. Shown are representative images under 400x magnification (scale bars, $50 \mu M$. (B) Body weight, $24 \mathrm{~h}$ urine protein, serum triglyceride, and serum cholesterol in 2, $12 \mathrm{M}$, and $12 \mathrm{M}-\mathrm{CR}$ rats. Data represents mean \pm standard deviation ( $\mathrm{n}=8$ in each group); ${ }^{*} \mathrm{P}<0.05,{ }^{* *} \mathrm{P}<0.01,{ }^{* *} \mathrm{P}<0.001,{ }^{* * *} \mathrm{P}<0.0001$. ns, not significant (one-way ANOVA with Turkey's post-hoc test).

7.0 software (GraphPad, San Diego, CA, USA). Normality of data distribution was assessed by Kolmogorov-Smirnov test and normally distributed data was represented as mean \pm standard deviation. To assess the effect of age and CR, the difference between groups was analyzed using one-way analysis of variance (ANOVA) followed by Tukey's posthoc test. A P value $<0.05$ was considered to be statistically significant.

\section{Results}

\section{Ageing causes renal dysfunction and changes in metabolic parameters which can be reversed by $C R$}

Given that ageing is associated with impaired kidney function and altered lipid metabolism (29), we initially determined histological changes in kidneys between 2 months $(2 \mathrm{M})$ and 12 months (12 M) old SD rats, both groups being fed ad libitum. The results showed that ageing induced fibrosis as evident in PAS staining (Figure 1A; top and middle panels). We next determined the differences in renal function and metabolic parameters between 2 and $12 \mathrm{M}$ $\mathrm{SD}$ rats. Since proteinuria is an early and definitive diagnostic criterion for renal dysfunction (30), we determined differences in $24 \mathrm{~h}$ urine protein content, which is the gold standard for the clinical determination of proteinuria (31). Body weight was significantly increased in $12 \mathrm{M}$ old rats $(463.5 \pm 8.4 \mathrm{~g})$ compared to $2 \mathrm{M}$ old rats $(343.5 \pm 10.4 \mathrm{~g} ; \mathrm{P}<0.01$ ) (Figure $1 B$ ). Serum triglyceride $(63.6 \pm 11.6 \mathrm{mg} / \mathrm{dL}$ in $12 \mathrm{M} v s .54 .6 \pm 13.5 \mathrm{mg} / \mathrm{dL}$ in $2 \mathrm{M} ; \mathrm{P}=0.1291)$ and cholesterol $(69.8 \pm 6.5 \mathrm{mg} / \mathrm{dL}$ in $12 \mathrm{M}$ vs. $60.4 \pm 6.5 \mathrm{mg} / \mathrm{dL}$ in $2 \mathrm{M} ; \mathrm{P}=0.1926)$ levels were higher, but did not reach statistical significance, in $12 \mathrm{M}$ old rats compared to $2 \mathrm{M}$ old rats (Figure $1 B$ ). Twelve $\mathrm{M}$ old rats had significantly higher renal dysfunction as assessed by $24 \mathrm{~h}$ urine protein content $(33.5 \pm 4.4 \mathrm{mg}$ in $12 \mathrm{M} v$ s. $1.95 \pm 1.04 \mathrm{mg}$ in $2 \mathrm{M} ; \mathrm{P}<0.0001$ ) (Figure $1 B$ ).

The same parameters were also evaluated in $12 \mathrm{M}$ old SD rats on CR (12 M-CR) to determine the effect of CR on renal dysfunction and metabolic parameters. Ageing associated fibrotic changes were reduced as evident by PAS staining (Figure 1A; bottom panels). Body weight in $12 \mathrm{M}-\mathrm{CR}$ 
A

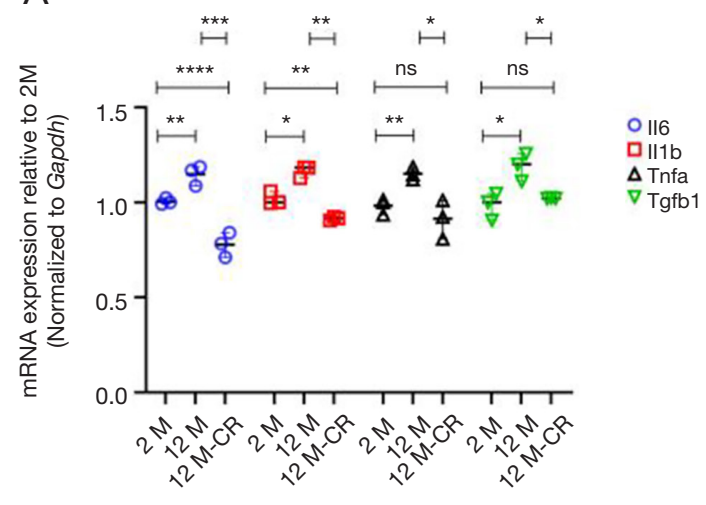

B

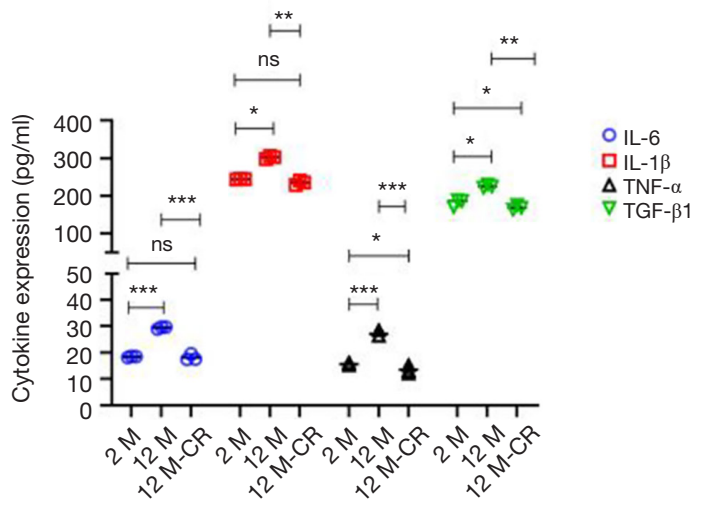

Figure 2 Ageing-induced induction of pro-inflammatory cytokines in the renal artery can be inhibited by caloric restriction. Experimental groups were young (2-month-old) and aged (12-month-old) rats fed ad libitum ( 2 and $12 \mathrm{M}$, respectively) or under 8 weeks of caloric restriction (12 M-CR). (A) Expression of the mRNA encoding the pro-inflammatory cytokines IL-6, IL-1 $\beta$, TNF- $\alpha$, and TGF- $\beta 1$ in the renal artery was determined using qRT-PCR. Data was normalized to GAPDH and expressed relative to expression in the $2 \mathrm{M}$ group. (B) Quantification of secreted IL-6, IL-1 $\beta$, TNF- $\alpha$, and TGF- $\beta 1$ in blood isolated from tail veins as determined by ELISA. Data in (A) and (B) represents mean \pm standard deviation ( $\mathrm{n}=8$ in each group) from three technical replicates; ${ }^{*} \mathrm{P}<0.05,{ }^{* *} \mathrm{P}<0.01,{ }^{* * *} \mathrm{P}<0.001,{ }^{* * * *} \mathrm{P}<0.0001$. $\mathrm{ns}$, not significant (one-way ANOVA with Turkey's post-hoc test).

rats $(287.3 \pm 3.5 \mathrm{~g})$ were significantly lower when compared to either $2 \mathrm{M}(\mathrm{P}<0.05)$ or $12 \mathrm{M}(\mathrm{P}<0.001)$ (Figure $1 B)$. Serum triglyceride $(38.4 \pm 7.6 \mathrm{mg} / \mathrm{dL} ; \mathrm{P}<0.001$ compared to $2 \mathrm{M}$ and $\mathrm{P}<0.0001$ compared to $12 \mathrm{M})$ and cholesterol $(48.0 \pm 9.1 \mathrm{mg} / \mathrm{dL}$ $\mathrm{P}<0.001$ compared to either 2 or $12 \mathrm{M}$ ) levels were also significantly lower in the $12 \mathrm{M}-\mathrm{CR}$ rats compared to either 2 or $12 \mathrm{M}$ (Figure $1 \mathrm{~B}$ ). The $24 \mathrm{~h}$ urine protein content in the $12 \mathrm{M}$-CR rats $(17.3 \pm 2.5 \mathrm{mg})$ was also significantly lower compared to both $2 \mathrm{M}(\mathrm{P}<0.05)$ and $12 \mathrm{M}(\mathrm{P}<0.05)$ groups (Figure $1 B$ ). Taken together, these results indicate that within the context of the SD rats used in the current study, CR is associated with the reversal of age-related changes in renal dysfunction and altered lipid metabolism.

\section{CR alleviates ageing-induced induction of pro-inflammatory cytokines in renal artery}

Ageing induced oxidative damage results in activation of the NF- $\kappa$ B signaling pathway ultimately leading to a cytokine storm (32). Indeed, ageing is associated with a pro-inflammatory shift in the vascular cytokine expression profile (13). Given the critical role of the renal artery in renal perfusion (8), and that ageing is an independent risk factor for both impaired renal function and vascular disorders (9), we next determined if the expression of pro-inflammatory cytokines increased in the renal artery with ageing, and if such an increase could be reversed by CR. We found ageing significantly increased mRNA expression of the inflammatory cytokines of $I L-6$, $I L-1 \beta, T N F-\alpha$, and $T G F-\beta 1$ in the renal artery (Figure $2 A)$. The expression of all four mRNAs was significantly decreased in the $12 \mathrm{M}$-CR group compared to the $12 \mathrm{M}$ group (Figure $2 A$ ). ELISA results showed a similar significant increase in serum IL-6 $(18.42 \pm 0.21 \mathrm{pg} / \mathrm{mL}$ in $2 \mathrm{M}$ vs. $29.47 \pm 0.41 \mathrm{pg} / \mathrm{mL}$ in $12 \mathrm{M} ; \mathrm{P}<0.001)$, IL- $\beta$ $(244.18 \pm 0.94 \mathrm{pg} / \mathrm{mL}$ in $2 \mathrm{M}$ vs. $301.85 \pm 4.24 \mathrm{pg} / \mathrm{mL}$ in $12 \mathrm{M} ; \mathrm{P}<0.05)$, TNF- $\alpha(15.61 \pm 0.58 \mathrm{pg} / \mathrm{mL}$ in $2 \mathrm{M} v s$. $27.13 \pm 1.20 \mathrm{pg} / \mathrm{mL}$ in $12 \mathrm{M} ; \mathrm{P}<0.001)$, and TGF- $\beta 1$ $(181.67 \pm 10.14 \mathrm{pg} / \mathrm{mL}$ in $2 \mathrm{M}$ vs. $225.56 \pm 4.19 \mathrm{pg} / \mathrm{mL}$ in $12 \mathrm{M} ; \mathrm{P}<0.05)$ in blood isolated from the tail vein of $12 \mathrm{M}$ rats compared to $2 \mathrm{M}$ rats. CR significantly decreased secretion of IL-6 $(18.16 \pm 1.21 \mathrm{pg} / \mathrm{mL} ; \mathrm{P}<0.001$ compared to $12 \mathrm{M})$, IL-1 $\beta(234.18 \pm 6.02 \mathrm{pg} / \mathrm{mL} ; \mathrm{P}<0.01$ compared to $12 \mathrm{M})$, TNF- $\alpha(13.51 \pm 1.59 \mathrm{pg} / \mathrm{mL} ; \mathrm{P}<0.001$ compared to $12 \mathrm{M})$, and TGF- $\beta 1(168.89 \pm 5.85 \mathrm{pg} / \mathrm{mL}$; $\mathrm{P}<0.01$ compared to $12 \mathrm{M}$ ) (Figure $2 \mathrm{~B}$ ). Cumulatively, these results show that $\mathrm{CR}$ is associated with the reversal of ageing induced expression of mRNA encoding proinflammatory cytokines in the renal artery and their serum levels. 
A

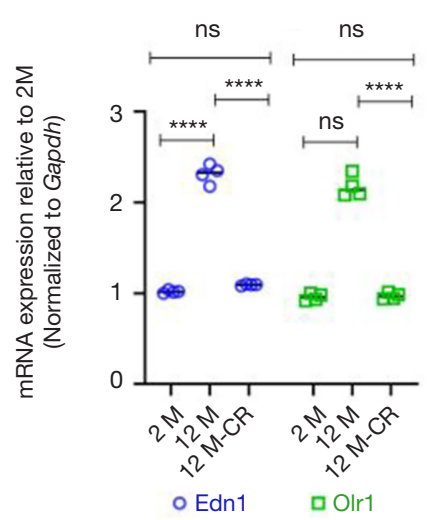

B

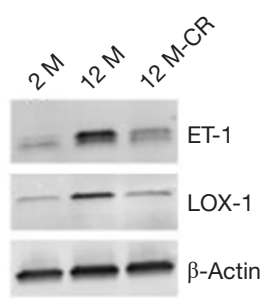

C

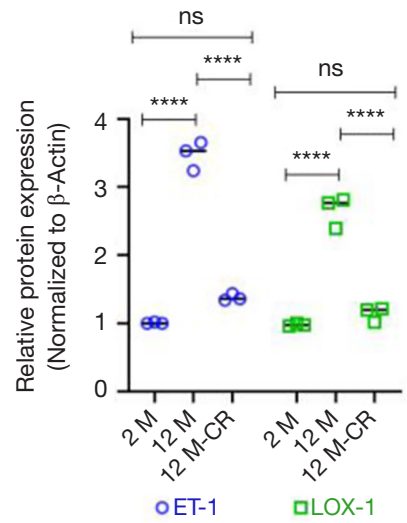

Figure 3 Expression of ET-1 increases with ageing in the renal artery but is inhibited with caloric restriction. Experimental groups were young ( 2 months-old) and aged (12 months-old) rats fed ad libitum ( 2 and $12 \mathrm{M}$, respectively) or under 8 weeks of caloric restriction (12 M-CR). (A) Expression of the Edn1 mRNA, which encodes ET-1 in the renal artery was determined using qRT-PCR. Data were normalized to GAPDH and expressed relative to expression in the $2 \mathrm{M}$ group. (B) Representative western blot images (obtained from one animal from each experimental group) showing expression of ET-1 and LOX-1 in the different experimental groups. $\beta$-Actin was used as a loading control. Please refer to Figure S1A for the corresponding uncropped blots. (C) Quantification of data shown in (B). Data in (A) and $(\mathrm{C})$ represents mean \pm standard deviation ( $\mathrm{n}=8$ in each group) from three technical replicates; ${ }^{* * * *} \mathrm{P}<0.0001$. ns, not significant (one-way ANOVA with Turkey's post-hoc test).

\section{Ageing induced expression of ET-1 in renal artery is reversed by $C R$}

Given that it has been earlier reported that ageing is associated with an increase in ET-1 expression in renal vasculature, which in turn increases the expression of LOX-1 and results in increased uptake of ox-LDL $(17,20,22)$, we next determined if the expression of ET-1 and LOX-1 changed within our model system, and if such changes were affected by CR. We found ageing induced significant increases in Edn1 (which encodes ET-1) and Olr1 (which encodes LOX-1) mRNA expression in the renal artery of 12 $\mathrm{M}$ old rats compared to $2 \mathrm{M}$ old rats (Figure 3A). Expression of both $E d n 1$ and $\operatorname{Or} 1 \mathrm{mRNA}$ was significantly decreased in the renal artery of $12 \mathrm{M}$-CR rats (Figure $3 A$ ). Immunoblot analysis revealed significant increases in ET-1 and LOX1 protein expression in the renal artery of $12 \mathrm{M}$ rats compared to $2 \mathrm{M}$ rats (ET-1: $3.47 \pm 0.21$ folds; $\mathrm{P}<0.0001$ and LOX-1: $2.66 \pm 0.23$ folds; $\mathrm{P}<0.0001$ ) (Figure $3 B, C$, Figure S1). CR significantly decreased both ET-1 (2.93 \pm 0.14 folds; $\mathrm{P}<0.0001)$ and LOX-1 $(2.46 \pm 0.39$ folds; $\mathrm{P}<0.0001)$ protein expression in the renal artery (Figure 3B,C). Cumulatively, these results indicate that $\mathrm{CR}$ is associated with the inhibition of ageing-induced increases in the expression of ET-1 in the renal artery.

\section{$C R$ potentially reduces expression of ET-1 in renal artery via suppression of $N F-\kappa B$ signaling}

Given that the expression of ET-1 increases with ageing, which is reversed by CR, we next asked how CR impacts the expression of ET-1 in the renal artery. The transcription factor NF-E2-related factor 2 (Nrf2) plays a central role in mitigating oxidative stress in healthy cells and is inactivated in ageing cells $(33,34)$. Oxidative stress mediated activation of NF- $\kappa \mathrm{B}$ signaling has been shown to regulate transcription of $E d n 1$ in multiple cell types including endothelial cells (35-37). The $E d n 1$ promoter has functional binding elements at position-2090 base pairs for NF- $\mathrm{KB}$ (38). CR can decrease oxidative stress partially by inducing histone deacetylase and gene repressor sirtuin 1 (SIRT1), which has been shown to decrease the production of ROS $(24,26,39)$. Hence, we determined if the ageing-induced increase in ET-1 expression observed in our experiments was due to the activation of NF- $\kappa \mathrm{B}$ signaling and/or inhibition of Nrf2-SIRT1 axis. Immunoblot analysis showed significant increases in phosphorylated P65 (7.27 \pm 0.41 folds; $\mathrm{P}<0.0001)$ and $\mathrm{I} \kappa \mathrm{B} \alpha(3.83 \pm 0.45$ folds; $\mathrm{P}<0.0001)$ in $12 \mathrm{M}$ rats compared to $2 \mathrm{M}$ rats (Figure 4, Figure S1), indicating the robust activation of $\mathrm{NF}-\kappa \mathrm{B}$ signaling with ageing in the renal artery. Phosphorylation of IкB $\alpha$ led to its 
A

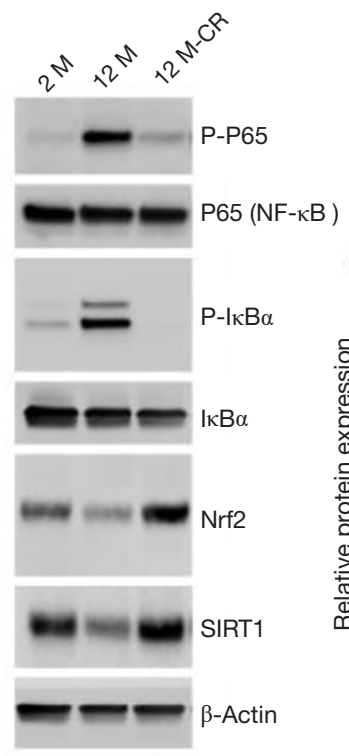

B

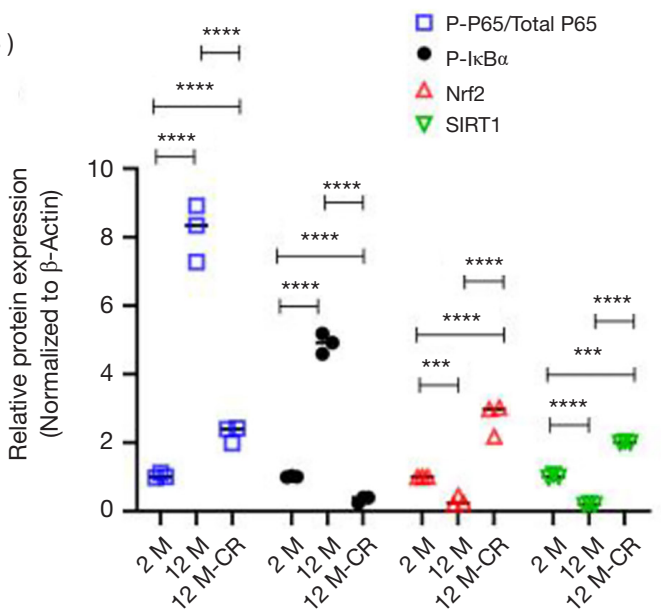

Figure 4 Caloric restriction-mediated reduction of ET-1 expression in the renal artery potentially occurs via the suppression of NF- $\kappa \mathrm{B}$ signaling. Experimental groups were young (2-month-old) and aged (12-month-old) rats fed ad libitum ( 2 and $12 \mathrm{M}$, respectively) or under 8 weeks of caloric restriction (12 M-CR). (A) Representative western blot images (obtained from one animal from each experimental group) showing the expression of phosphorylated and total P65 and I $\mathrm{B} \alpha, \mathrm{Nrf2}$, and SIRT1 in the different experimental groups. $\beta$-Actin was used as a loading control. Please refer to Figure S1B for the corresponding uncropped blots. (B) Quantification of data shown in (A). Data in (B) represents mean \pm standard deviation ( $\mathrm{n}=8$ in each group) from three technical replicates; ${ }^{* * *} \mathrm{P}<0.001,{ }^{* * *} \mathrm{P}<0.0001$ (one-way ANOVA with Turkey's post-hoc test).

degradation, releasing P65, which can be phosphorylated and translocated to the nucleus, ultimately resulting in transcriptional upregulation of target genes of the NF- $\mathrm{\kappa B}$ signaling pathway (32). Expression of Nrf2 (5.03 \pm 0.04 folds; $\mathrm{P}<0.001)$ and SIRT1 $(3.97 \pm 0.03$ folds; $\mathrm{P}<0.0001)$ significantly decreased in $12 \mathrm{M}$ rats compared to $2 \mathrm{M}$ rats (Figure 4). However, phosphorylated P65 and IкB $\alpha$ were significantly downregulated, whereas expression of $\mathrm{Nrf} 2$ and SIRT1 were upregulated, in the renal arteries of $12 \mathrm{M}-\mathrm{CR}$ rats (Figure 4). These results cumulatively indicate that ageing mediated activation of ET-1 expression is potentially being mediated by the activation of NF- $\mathrm{BB}$ signaling, whereas CR inhibits ET-1 expression both by inactivation of NF- $\mathrm{BB}$ signaling and activation of Nrf2-SIRT1.

\section{Discussion}

Life expectancy is projected to increase to 91 years for women and 88 years for men by 2030 (29) and age related chronic kidney disease is already becoming a serious medical concern associated with ageing $(3,4,7,14,29,40,41)$.
Hence it is of paramount importance to define underlying pathogenic mechanisms associated with ageing-induced renal dysfunction and identify potential therapeutic targets. $\mathrm{CR}$, a reduction in calorie intake without malnutrition, is a powerful intervention known for decades to slow down aging and increase lifespan across different species (42-44). The results from the current study provide evidence that ageing induced expression of ET-1 in the renal arteries of 12 -month-old rats can be inhibited by $30 \%$ CR. Given the critical role of the renal arterioles in renal perfusion (8), and ageing is an independent risk factor for both impaired renal function, the results are potentially applicable to renal dysfunction in ageing.

Our results corroborate previous findings that CR can prevent impaired renal function (6). Indeed, inhibition of ET-1 activity by the use of antagonists against its receptors are already in different stages of pre-clinical and clinical studies $(8,22,45,46)$. Our results suggest that CR, alone or in combination with endothelin receptor antagonists, should be tested in pre-clinical studies to test its efficacy in rescuing ageing-induced renal dysfunction. 
CR improved $24 \mathrm{~h}$ urine protein and also serum triglyceride and cholesterol, corroborating previous findings of an intricate relationship between lipid metabolism and ageing in the kidney (47-50). ET-1 is an important player in the development of renal disease (51), as renal arteries are particularly sensitive to it (52). Our results also suggest that ET-1 has direct effects on the renal artery, in regulating the pro-inflammatory factors which are mediated by LOX-1 (20). Given that $\mathrm{CR}$ reduced the levels of ET- 1 in the renal artery, it is entirely possible that this is one of the mechanisms of CR-mediated rescue of renal function in ageing rats. It is highly likely that CR induced changes in other tissues such as the fat content, and contributed to reducing inflammation and kidney injury in the ageing rats. Hence, the systemic effect of CR on other organs needs to be investigated in future studies.

Expression of ET-1 is regulated at multiple levels (36), and whether CR-mediated regulation of ET-1 expression is exclusively regulated by activation of $\mathrm{NF}-\mathrm{\kappa B}$ signaling in the ageing renal artery remains to be determined. However, the overall upregulation of inflammatory proteins and alterations in lipid metabolism as observed in the current study point to a critical role of NF- $\mathrm{\kappa B}$ signaling in ageing associated renal dysfunction. In addition it remains to be determined how CR increases the expression of $\mathrm{Nrf} 2$ and SIRT1, both of which contribute to attenuation of oxidative stress $(26,33)$. It might be possible that CR increases glutathione-S-transferase, that in turn, induces SIRT1 and Nrf2 $(33,36)$, or the increase may be a feedback regulation of ROS reduced oxidative stress.

In summary, the results from the current study indicate that even a moderate $(30 \%)$ CR can be beneficial in reversing age related kidney dysfunction, potentially by reducing the expression of ET-1. It remains to be determined if the decrease in pro-inflammatory cytokines and lipid metabolites observed after CR were due to decreased ET-1 expression. Alternatively, this could be mediated by additional unknown targets that were being modified by CR. Nonetheless, CR might be a potent alternative to prevent ageing induced renal artery alterations. There major limitation to the current study is that the renal arterioles are the major resistance vessels regulating renal blood flow and glomerular filtration rate, not the renal arteries. However, due to limitations in the volume of the experimental rats, the renal arterioles of the rats were difficult to separate and obtain, so the renal arteries were used in present study.

\section{Acknowledgments}

Funding: None.

\section{Footnote}

Reporting Checklist: The authors have completed the ARRIVE reporting checklist. Available at https://dx.doi. org/10.21037/atm-21-2218

Data Sharing Statement: Available at https://dx.doi. org/10.21037/atm-21-2218

Conflicts of Interest: All authors have completed the ICMJE uniform disclosure form (available at https://dx.doi. org/10.21037/atm-21-2218). The authors have no conflicts of interest to declare.

Ethical Statement: The authors are accountable for all aspects of the work in ensuring that questions related to the accuracy or integrity of any part of the work are appropriately investigated and resolved. All animal experiments were approved by the Institutional Animal Care and Use Committee of the Second Medical Center, Chinese PLA General Hospital under a project license (No. PLA301-2020-3XNK-2162), in compliance with all applicable international, national or institutional guidelines for the care and use of animals.

Open Access Statement: This is an Open Access article distributed in accordance with the Creative Commons Attribution-NonCommercial-NoDerivs 4.0 International License (CC BY-NC-ND 4.0), which permits the noncommercial replication and distribution of the article with the strict proviso that no changes or edits are made and the original work is properly cited (including links to both the formal publication through the relevant DOI and the license). See: https://creativecommons.org/licenses/by-nc-nd/4.0/.

\section{References}

1. Oeppen J, Vaupel JW. Demography. Broken limits to life expectancy. Science 2002;296:1029-31.

2. Kochanek KD, Murphy SL, Xu J, et al. Deaths: Final Data for 2017. Natl Vital Stat Rep 2019;68:1-77. 
3. Levey AS, Inker LA, Coresh J. Chronic Kidney Disease in Older People. JAMA 2015;314:557-8.

4. Docherty MH, O'Sullivan ED, Bonventre JV, et al. Cellular Senescence in the Kidney. J Am Soc Nephrol 2019;30:726-36.

5. Valentijn FA, Falke LL, Nguyen TQ, et al. Cellular senescence in the aging and diseased kidney. J Cell Commun Signal 2018;12:69-82.

6. Wiggins JE, Goyal M, Sanden SK, et al. Podocyte hypertrophy, "adaptation," and "decompensation" associated with glomerular enlargement and glomerulosclerosis in the aging rat: prevention by calorie restriction. J Am Soc Nephrol 2005;16:2953-66.

7. Yang H, Fogo AB. Cell senescence in the aging kidney. J Am Soc Nephrol 2010;21:1436-9.

8. Meyer MR, Rosemann T, Barton M, et al. GPER Mediates Functional Endothelial Aging in Renal Arteries. Pharmacology 2017;100:188-93.

9. Barton M, Husmann M, Meyer MR. Accelerated Vascular Aging as a Paradigm for Hypertensive Vascular Disease: Prevention and Therapy. Can J Cardiol 2016;32:680-6.e4.

10. Huang N, Foster MC, Mitchell GF, et al. Aortic stiffness and change in glomerular filtration rate and albuminuria in older people. Nephrol Dial Transplant 2017;32:677-84.

11. Jia G, Aroor AR, Sowers JR. Arterial Stiffness: A Nexus between Cardiac and Renal Disease. Cardiorenal Med 2014;4:60-71.

12. Bolignano D, Mattace-Raso F, Sijbrands EJ, et al. The aging kidney revisited: a systematic review. Ageing Res Rev 2014;14:65-80.

13. Csiszar A, Sosnowska D, Wang M, et al. Age-associated proinflammatory secretory phenotype in vascular smooth muscle cells from the non-human primate Macaca mulatta: reversal by resveratrol treatment. J Gerontol A Biol Sci Med Sci 2012;67:811-20.

14. Baylis C, Corman B. The aging kidney: insights from experimental studies. J Am Soc Nephrol 1998;9:699-709.

15. Vignon-Zellweger N, Heiden S, Miyauchi T, et al. Endothelin and endothelin receptors in the renal and cardiovascular systems. Life Sci 2012;91:490-500.

16. Hocher B, Thone-Reineke C, Rohmeiss P, et al. Endothelin-1 transgenic mice develop glomerulosclerosis, interstitial fibrosis, and renal cysts but not hypertension. J Clin Invest 1997;99:1380-9.

17. Goettsch W, Lattmann T, Amann K, et al. Increased expression of endothelin-1 and inducible nitric oxide synthase isoform II in aging arteries in vivo: implications for atherosclerosis. Biochem Biophys Res Commun
2001;280:908-13.

18. Li L, Fink GD, Watts SW, et al. Endothelin-1 increases vascular superoxide via endothelin(A)-NADPH oxidase pathway in low-renin hypertension. Circulation 2003;107:1053-8.

19. Wedgwood S, McMullan DM, Bekker JM, et al. Role for endothelin-1-induced superoxide and peroxynitrite production in rebound pulmonary hypertension associated with inhaled nitric oxide therapy. Circ Res 2001;89:357-64.

20. Morawietz H, Duerrschmidt N, Niemann B, et al. Induction of the oxLDL receptor LOX-1 by endothelin-1 in human endothelial cells. Biochem Biophys Res Commun 2001;284:961-5.

21. Barton M. Aging and endothelin: determinants of disease. Life Sci 2014;118:97-109.

22. Ortmann J, Amann K, Brandes RP, et al. Role of podocytes for reversal of glomerulosclerosis and proteinuria in the aging kidney after endothelin inhibition. Hypertension 2004;44:974-81.

23. Berner YN, Stern F. Energy restriction controls aging through neuroendocrine signal transduction. Ageing Res Rev 2004;3:189-98.

24. Ungvari Z, Parrado-Fernandez C, Csiszar A, et al. Mechanisms underlying caloric restriction and lifespan regulation: implications for vascular aging. Circ Res 2008;102:519-28.

25. Walker AE, Henson GD, Reihl KD, et al. Beneficial effects of lifelong caloric restriction on endothelial function are greater in conduit arteries compared to cerebral resistance arteries. Age (Dordr) 2014;36:559-69.

26. Csiszar A, Labinskyy N, Jimenez R, et al. Anti-oxidative and anti-inflammatory vasoprotective effects of caloric restriction in aging: role of circulating factors and SIRT1. Mech Ageing Dev 2009;130:518-27.

27. Csiszar A, Sosnowska D, Tucsek Z, et al. Circulating factors induced by caloric restriction in the nonhuman primate Macaca mulatta activate angiogenic processes in endothelial cells. J Gerontol A Biol Sci Med Sci 2013;68:235-49.

28. Horrillo D, Sierra J, Arribas C, et al. Age-associated development of inflammation in Wistar rats: Effects of caloric restriction. Arch Physiol Biochem 2011;117:140-50.

29. Tonelli M, Riella M. Chronic kidney disease and the aging population. Am J Nephrol 2014;39:248-51.

30. Levey AS, de Jong PE, Coresh J, et al. The definition, classification, and prognosis of chronic kidney disease: a 
KDIGO Controversies Conference report. Kidney Int 2011;80:17-28.

31. Fox CS, Larson MG, Leip EP, et al. Predictors of newonset kidney disease in a community-based population. JAMA 2004;291:844-50.

32. Weiss EP, Fontana L. Caloric restriction: powerful protection for the aging heart and vasculature. Am J Physiol Heart Circ Physiol 2011;301:H1205-19.

33. Kobayashi M, Yamamoto M. Nrf2-Keap1 regulation of cellular defense mechanisms against electrophiles and reactive oxygen species. Adv Enzyme Regul 2006;46:113-40.

34. Nguyen T, Nioi P, Pickett CB. The Nrf2-antioxidant response element signaling pathway and its activation by oxidative stress. J Biol Chem 2009;284:13291-5.

35. Park JY, Kim YM, Song HS, et al. Oleic acid induces endothelin-1 expression through activation of protein kinase C and NF-kappa B. Biochem Biophys Res Commun 2003;303:891-5.

36. Stow LR, Jacobs ME, Wingo CS, et al. Endothelin-1 gene regulation. FASEB J 2011;25:16-28.

37. Terragni J, Graham JR, Adams KW, et al. Phosphatidylinositol 3-kinase signaling in proliferating cells maintains an anti-apoptotic transcriptional program mediated by inhibition of FOXO and non-canonical activation of NFkappaB transcription factors. BMC Cell Biol 2008;9:6.

38. Quehenberger P, Bierhaus A, Fasching P, et al. Endothelin 1 transcription is controlled by nuclear factor-kappaB in AGE-stimulated cultured endothelial cells. Diabetes 2000;49:1561-70.

39. Ungvari Z, Bailey-Downs L, Gautam T, et al. Ageassociated vascular oxidative stress, Nrf2 dysfunction, and NF-\{kappa\}B activation in the nonhuman primate Macaca mulatta. J Gerontol A Biol Sci Med Sci 2011;66:866-75.

40. Zheng F, Plati AR, Banerjee A, et al. The molecular basis of age-related kidney disease. Sci Aging Knowledge Environ 2003;2003:PE20.

41. Zhou XJ, Saxena R, Liu Z, et al. Renal senescence in 2008: progress and challenges. Int Urol Nephrol

Cite this article as: Wang XH, Ao QG, Cheng QL. Caloric restriction inhibits renal artery ageing by reducing endothelin-1 expression. Ann Transl Med 2021;9(12):979. doi: 10.21037/ atm-21-2218
2008;40:823-39.

42. Piper MD, Bartke A. Diet and aging. Cell Metab 2008;8:99-104.

43. McDonald RB, Ramsey JJ. Honoring Clive McCay and 75 years of calorie restriction research. J Nutr 2010;140:1205-10.

44. Patel SA, Velingkaar N, Makwana K, et al. Calorie restriction regulates circadian clock gene expression through BMAL1 dependent and independent mechanisms. Sci Rep 2016;6:25970.

45. Kohan DE, Pollock DM. Endothelin antagonists for diabetic and non-diabetic chronic kidney disease. Br J Clin Pharmacol 2013;76:573-9.

46. Kowalczyk A, Kleniewska P, Kolodziejczyk M, et al. The role of endothelin-1 and endothelin receptor antagonists in inflammatory response and sepsis. Arch Immunol Ther Exp (Warsz) 2015;63:41-52.

47. Braun F, Rinschen MM, Bartels V, et al. Altered lipid metabolism in the aging kidney identified by three layered omic analysis. Aging (Albany NY) 2016;8:441-57.

48. Anisimov VN, Berstein LM, Egormin PA, et al. Metformin slows down aging and extends life span of female SHR mice. Cell Cycle 2008;7:2769-73.

49. Dong D, Cai GY, Ning YC, et al. Alleviation of senescence and epithelial-mesenchymal transition in aging kidney by short-term caloric restriction and caloric restriction mimetics via modulation of AMPK/mTOR signaling. Oncotarget 2017;8:16109-21.

50. Everitt AV, Porter BD, Wyndham JR. Effects of caloric intake and dietary composition on the development of proteinuria, age-associated renal disease and longevity in the male rat. Gerontology 1982;28:168-75.

51. Kohan DE, Barton M. Endothelin and endothelin antagonists in chronic kidney disease. Kidney Int 2014;86:896-904.

52. Widmer CC, Mundy AL, Kretz M, et al. Marked heterogeneity of endothelin-mediated contractility and contraction dynamics in mouse renal and femoral arteries. Exp Biol Med (Maywood) 2006;231:777-81.

(English Language Editor: B. Draper) 
A

Uncropped blots for Figure $3 B$

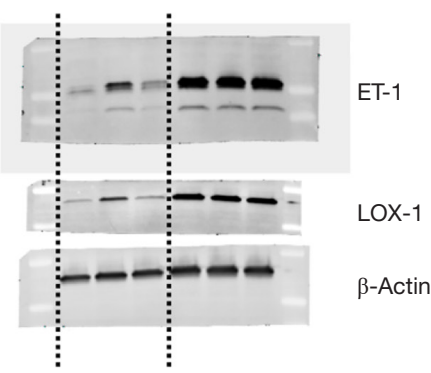

B Uncropped blots for Figure $4 A$

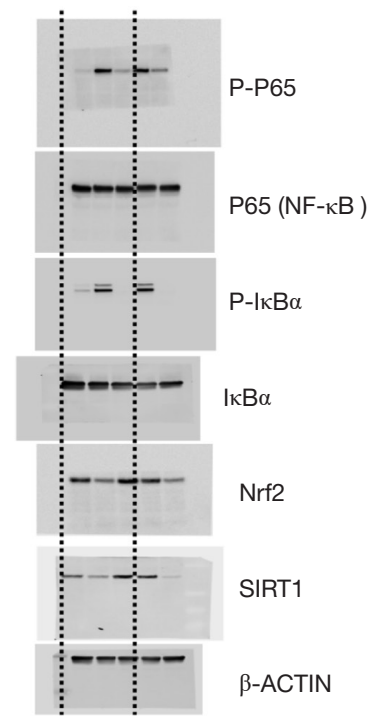

Figure $\mathbf{S} 1$ The corresponding uncropped blots about the Figures $3 B$ and $4 A$. 